\title{
Chapter 3 \\ The Systemic Nature of the Global Crisis and Some Principles for Tackling It
}

\author{
Christian Ghymers
}

\begin{abstract}
This chapter argues that climate change, the global macroeconomic crisis and the weakening of democracy are all expressions of the same incoherence in the present global economic system, which operates on the basis of major 'market failures' that are characterized by the same kind of economic mechanism based on biased relative prices for fossil energies, financial returns and social cohesion. Therefore, the only practical solution is to make sustainable production profitable by first correcting these relative prices in order to re-establish a systemic convergence between private and social returns and between political and economic democracy.
\end{abstract}

\section{A Holistic View, A Concerning Diagnostic}

The crisis is systemic...

One of the important results of the comparative analysis undertaken in the Monnet Network is the awareness of systemic nature of what is commonly referred to as 'the crisis'. This result leads to a serious consideration of the hypothesis of unsustainability in the present global economic order. The emergence and persistence of the global crisis of 2008-2009, which became in the following decade (2010-2019) a global crisis of democracy in Western societies, announce a clear rupture with respect to the dominant Western models of governance and relationships among citizens. Beyond this observation, which is slowly being shared by a growing number of observers, the changes presently underway involve not only an adaptation of socioeconomic policies in Europe and Latin America to new constraints but also a more radical revision of the dominant paradigms of the world economy. Therefore, this chapter focuses on the systemic aspects of the global crisis that affects both regions and the rest of the world in order to prioritize the design of a coherent solution for particular regions.

\footnotetext{
C. Ghymers $(\bowtie)$

Founder and Co-coordinator of the Jean Monnet Network "Crisis-Equity-Democracy

for Europe and Latin America”, IRELAC, Brussels, Belgium
} 
.... and global, characterized by unsustainability from macroeconomic policies to democracy and the environment ....

Indeed, the crisis is global, not just in the geographical sense but also in the systemic sense for being the manifestation of economic behaviours that accumulate, the costs of which are passed on to subsequent generations with an exponentially growing price. The most emblematic and fatal consequence is global warming, which should lead soon to a general unsustainability of the present economic and sociopolitical order. This unsustainability is not only limited to the environment, with climate change, but also concerns the macroeconomic aspects of our economies, with a slowdown in growth and productivity, a lack of room for manoeuvres in both monetary and fiscal policies, a concerning accumulation of debts and financial weaknesses, inefficiencies in financial globalization that increases pro-cyclical instabilities, allocation of global savings towards overconsumption and involvement of a massive waste of resources and of $\mathrm{CO}_{2}$ emissions by the richest economies, which are not moving towards more beneficial and sustainable productive investments. Unfair income distribution and insufficient welfare expenditures increase and drive our societies towards political deadlock, exposing democracies to populist waves and ultimately to the destruction of life on the planet. Paradoxically, climate change, which is the worst global dimension of the present sustainability crisis, is not effectively prioritized either by policymakers and public opinion - except the recent wake-up call from the youth ${ }^{1}$ - or by economists. This amazing procrastination threatens life on the planet and is dramatically increasing the costs of any solution.

...which are linked together...

The key thesis of this chapter is that climate change, the global macroeconomic crisis and the weakening of democracy are all expressions of the same incoherence in the current global economic system, which operates on the basis of the same principle, 'market failures'; i.e. those who cause damage to others do not pay for it because biased relative prices do not incorporate fatal external effects: overly low costs or no cost at all for carbon emissions, overly high relative returns for financial activities with respect to productive activities and overly high prices for safe assets in US dollars (overly low yields).

'Climate change is a result of the greatest market failure the world has seen' (Stern 2007) and the most emblematic consequence of the systemic unsustainability that results from the overwhelming short-termism of our materialist rationality, whatever be the ideological option (right or left). All these phenomena of dysfunctional behaviours share a common systemic origin and respond to the same kind of simple economic mechanisms through biased relative prices: the fact that numerous important economic decisions are biases due to being mainly taken on the basis of short-term, distorted, short-sighted price systems that amplify their damaging future effects (social, economic and political). Furthermore, both climate change and

\footnotetext{
${ }^{1}$ Although it is an important step for spreading awareness in public opinion, this emerging movement is still very unprepared and does not push concrete measures.
} 
financial/macroeconomic instability are also linked to financial reasons and are a result of the same disinformation from vested interests. This short-termism and materialist rationality rely, of course, upon values, but changing them is a much more complex issue than changing relative prices and fighting against lobbies.

The reasons for such linked inefficiencies are explained below. It is a complex result from a combination of financial flows, dogmatic views, deeper mental structures that prefer short-term advantages and sociopolitical features manipulated by vested interests. In spite of these very resilient ultimate causes, these risky and costly defects could be fixed with simple technical solutions insofar as they address the same basic action mechanisms of these price distortions by using adjusted individual incentives. They all come either from market or administrated prices that do not correctly incorporate the externalities of these decentralized decisions or from a lack of collective goods or their abuse by not paying adequately for them. In both cases, relative prices are misleading. These typical situations of market failures are characterized by a systemic divergence between private and social returns, which creates a typical moral hazard that inevitably leads to unsustainability. Therefore, it is futile and even counterproductive to try to attack the effects without correcting first the systemic mechanisms. Furthermore, the different areas of unsustainability even mutually reinforce each other, which explains the unsustainability and inevitable collapse of the present regime: macroeconomic and financial architecture caveats feed global warming by diverting financial flows. The manipulation of democracy and an increasingly unfair income distribution maintain the unsustainability of these linked processes, which are a threat to democracy itself.

.... and illustrated by three relevant cases of distortion...

We single out three emblematic cases of these mutually supportive price distortions or incorrect market signals that make the present system not only inefficient but also contradictory to economic efficiency and unsustainable, not only economically but also socially and therefore politically:

- The use of a national currency - the US dollar - as the main vehicle of international payments and reserves makes the public good of the international monetary system (IMS) asymmetric, impeding its management for world interests (Triffin dilemma ${ }^{2}$ ); this dollar-based IMS generates several distortions and significant spillovers upon the rest of the world: automatic financing of US external and fiscal deficits at lower interest rates (price distortion) by capturing the world demand for safe assets in order to allocate global savings to US overconsumption by playing the role of international banking transformation. This function biases the US policy mix towards expansionist, pro-consumption monetary policies and causes significant spillovers upon the rest of the world including mismanagement of global liquidities, accumulation of financial risks and overly low savings

\footnotetext{
${ }^{2}$ The Triffin dilemma expresses the simple fact that increasing international liquidity means increasing the external liabilities of the US economy, the currency of which is demanded as an international reserve; this fact leads to the logical impossibility of regulating global liquidity and managing an optimal policy mix in the USA, which provokes global liquidity cycles and global macroeconomic instability.
} 
(public good failures). This asymmetric IMS is so dysfunctional and unsustainable that the gap between the (increasing) power of unilateral US monetary policy and the (decreasing) relative weight of the US economy has risen dramatically with the explosive increase of free international financial flows, the growing role of global banks operating in dollars and the rapid development of emerging economies resulting from the so-called globalization.

- The excessive financial globalization and deregulation promoted by the dollarbased IMS have led to another kind of moral hazard provoked by key price distortions and lack of regulations: the higher profitability of financial speculation with respect to production activities creates economic instability and high costs because deregulated financial systems mechanistically propagate shocks and endogenous financial crises which have amplified macroeconomic crises; financial markets are not the same as other markets because operators are dependent upon the liquidity condition, which is a public good.

- More generally regarding non-financial markets, some significant price distortions also result from the inadequate internalization of the externalities issued by decentralized economic actors; it is the same kind of inner near-sightedness of any decentralized (competitive) price system when prices do not incorporate all the information or do not take adequate account of spillover effects, as is the case for environmental damages and especially the very inadequate (or absent) price on carbon emission.

The parallel between the damages caused by the excessive emission of $\mathrm{CO}_{2}$ and the excessive spillovers resulting from the conjunction of an asymmetric IMS and untamed free financial markets deserves especial attention. It is not just a similarity but an intertwined cumulative process. In concrete, positive terms, to reach the neutral carbon output required for our survival as living species, crucial changes in relative prices are urgently needed not only for the internalization of all carbon footprints but also for the IMS and financial markets in order to correct relative financial returns capable of ensuring the (very) large financial flows required for making possible and directly profitable the output changes towards a low-carbon system in the emerging economies and other LDCs. Also, the manipulation of public opinion and policymakers is very similar in these three cases, with a combination of simplistic dogmatism and rent-seeking by using financial resources to corrupt decision-makers or misinform citizens.

... which form a pyramid of systemic unsustainability...

These three global destabilizing mechanisms are related and mutually supportive both in their deeper causal origin and methods and in their functional connections for a restoration of profitable sustainability and a change in the order based upon inequality/power imbalances and the resulting lack of multilateral organization/ international cooperation. Indeed, the caveats of an asymmetric IMS allow for maintaining international power for the US economy and oligarchic interests in the rest of the world on the part of financial policymakers in central banks and treasuries. This status quo combination makes global warming worse and impedes a systemic solution towards a sustainable economic order on the planet. 
The lack of external constraint for the USA allows for the sustaining of a more expansionist policy mix by accelerating the cheap financial inflows necessary for feeding the global macroeconomic imbalances inherent to the (unsustainable) US consumption way-of-life. This imbalance is closely linked to the need to import external savings and to control fossil fuel markets. ${ }^{3}$ Financial globalization through large multinational banks operating basically in dollars is a complementary part of the system based upon the free-market tale that permits an extension of unproductive financial capitalism. This extension is necessary for feeding the macroeconomic imbalances as well as for sustaining the political bias and the manipulation that are necessary to the status quo but that contribute to increases in the gap between economic and political democracy.

The result is an excessive and counterproductive financial globalization because capital movements flow in the wrong direction for sustainable economic development: from poor to rich economies and from real investments to financial ones, exposing the world to global macroeconomic disequilibrium and to the launch of negative spillovers through a pro-cyclical, global financial cycle with perverse effects upon exchange rates, capital flows, growth, savings and the environment. These three major distortions are related to - and consolidate - inequality and power abuses, thus manifesting an increasing gap between political and economic democracy. There is a total correspondence between those who benefit the most from $\mathrm{CO}_{2}$ emissions and those who suffer the most from global warming. Rising temperatures will cause the poorest to suffer the most, even in the wealthiest nation in the world (Hsiang et al. 2017). In parallel, it is now obvious that the hypertrophy in the financial sector not only was not favourable to growth and social mobility but also increased social costs, inequality and political instability. This growing divergence between political and economic democracy is the main visible manifestation of the inner contradiction upon which the economic system has lost its rationality through fundamental relative price distortions that lead to destructive results that in turn create mistrust in democratic institutions, which feeds the rapid expansion of populism. This is a fatal paradox since materialism leads to its own contradiction by destroying the basis of material welfare and life.

...in which the unfounded belief in the efficiency of financial markets bears a very heavy responsibility...

The radical neo-liberal reaction to the Triffin dilemma was free floating and financial liberalization. Indeed, abandoning most of the regulations inhibiting capital movements appeared as the easiest and most coherent action in a binary reaction against state intervention to face imbalances developed under less liberal policies. Such a dogma was based upon the simplistic belief that financial markets would necessarily be as efficient as any product market by fixing competitive asset prices and yields as a result of their fundamental value.

This is an epistemological mistake that has triggered new mechanisms of additional macroeconomic imbalances. The paradigm of financial market efficiency

\footnotetext{
${ }^{3}$ Oil is traded in US dollars, like coal used to be traded in British $£$, when the $£$ was the main key currency.
} 
plays a complementary role in the transmission of the 'built-in destabilizer' (Ghymers 1986; Triffin 1991) in the dollar system. The reason is merely that financial markets do not operate in the same way as product and service markets because the behaviours of financial operators are not independent but linked through mimetic competition to their assessment of liquidity conditions, which tends to be self-fulfilling. This absence of operator independence impedes the efficiency of financial markets and explains their inherent instability. Unlike in other markets, credit demand and supply move together with liquidity conditions, keeping yields and interest rates from playing the balancing role of 'objective' market prices. As shown by Aglietta (2018), in Minsky's (1982) line of Keynes' interpretation, financial market behaviours are not governed like other markets by the objective fundamental value of assets with a symmetry of information but by liquidity, which is mainly self-fulfilling and makes financial operators mutually dependent: liquidity intrinsically reflects this interdependency because financial markets operate under 'mimetic competition' (Orléan 1999) when forming expectations of asset values and debt sustainability: credit providers tend to expect the same kind of valuation change in asset prices as borrowers do. This link biases the credit market indicators towards a one-way bet. Therefore, credit demand and supply cannot ensure a stable equilibrium through yield changes like other markets used to do because demand and supply move together. Contrary to non-financial markets, in which the two sides of the market have opposing interests with regard to prices since demand is subject to saturation condition (i.e. the demand slope is negative), financial markets are inherently unstable and inevitably generate a succession of euphoria and panic as a result of their subjective common perceptions of liquidity, which link credit demand and supply: the credit demand slope could be positive when the expected change in asset value is higher than the costs of borrowing, but since this expectation is shared by both borrowers and credit suppliers on financial markets, the expected yields cannot have the stabilization role of normal competitive market prices. Liquidity is selffulfilling and pro-cyclical: in the cyclical upwards phase, optimistic expectations increase the demand for credit even with interest rate increases, while lenders increase also their supply of credit since they perceive fewer business risks and since their collaterals acquire more value. Paradoxically, indebtedness tends to contract the risk premium. When the cyclical bubble bursts, the same cumulative process is in motion on the negative side: asset values decrease while debt values remain (or even increase in real terms), moving back credit supply and demand. The deterioration of debtors directly affects that of creditors and lenders, triggering a deleverage adjustment process that has macroeconomic depressing effects (balance sheet recession). Mimetic competition is necessarily biased towards pro-cyclical behaviour, impeding the self-regulation of liquidity by credit price adjustments.

Here the market price distortion comes from the fact that financial prices are selfcorrelated through liquidity perceptions by both sides of financial markets, which creates a destabilizing financial cycle. In the past 30 years, the size of global finance in 
the world economy has been moving from 280\% of GDP to 430\% (Artus 2019), ${ }^{4}$ and the causality relation between the real cycle and the financial cycle has been reversed: the financial cycle explains the real cycle in the period of 1996-2018 while the contrary was true from 1980 to 1995. Except for emerging economies, the size of finance is not favourable to growth. Furthermore, Artus (2019) shows that the gravity of recession increases with the size of finance in the GDP and the 'allocative efficiency' of savings has been a concern since 1990, in the sense that savings have been oriented mainly towards inefficient uses such as real estate or public consumption and not towards productive investments. These contradictory economic results should call into question the paradigm of financial market efficiency. Facts show that market incentives are biased towards a hyper-development of financial capitalism. Distortions in market incentives have induced non-financial business to reduce its deficit (dissaving) to become a surplus (saving) sector in almost all industrial countries: real investments have been reduced in favour of financial investments, the stock of real assets has been declining relative to financial assets, job creation and economic growth have slowed, and unemployment has risen, such that even stability-oriented countries such as Germany have been running budget deficits most of the time. Given the positive interest-growth differential, the public debt-to-GDP ratio has risen strongly, leading to over-indebtedness. At the same time and as a consequence of the easiness to "make money with money' in financial capitalism, a process of growing income inequality has started to increase the gap between political and economic power, strengthening the lobbies and amplifying the incoherence in the economic rationality. This feature is at the very centre of the political, economic and moral crisis facing humanity: economic power - ownership of financial resources in the hands of few - tends to become immune to economic democracy, in contrast to the three first decades of the post-war period, a period that showed a development of market economies oriented towards real output and quasi-full employment.

...but remains unable to answer to the threat of global warming.

On top of this macroeconomic disequilibrium leading that has led to the political crisis of the emerging populism is the unsustainability of the present Anthropocene epoch: the fact that the acceleration of the influence of human behaviour on Earth's atmosphere in recent decades is threatening the existence of humankind as a biological species. This constraint is by definition the most global ever faced, but it is also more radical than the previous ones faced by human societies insofar as - contrary to past economic constraints - the irreversibility of the damages for the planet calls into question the existence of human life itself, not to mention the costs. In the past, human societies faced many serious constraints but generally not the global life system, and the successive constraints were successfully bypassed as a result of the genetic basic instinct of our species for dominating and exploiting the Earth, especially when translated into the materialist rationalism which has been shaping our societies since the eighteenth century Enlightenment and its consequent expanding industrial revolutions.

\footnotetext{
${ }^{4}$ These numbers are based upon Natixis data: finance weight is measured as the total of outstanding loans, bonds, stock market capitalization and M2 money stock divided by world GDP at current prices.
} 


\title{
How to Explain the Absence of a Coherent Reaction to the Present Unsustainability of the World Economy?
}

\author{
The procrastination of all policymakers facing the three main facets of the systemic \\ unsustainability... \\ It is really amazing that the global warming which has been scientifically identified \\ for at least half a century as an inescapable consequence of our consumption of fossil \\ energies remains without any significant counteraction in spite of the dramatic \\ increase of the costs of inaction. Neither the ecologists nor the economists - with \\ minor exceptions - have formulated adequate reactions. Trying to explain this irratio- \\ nal behaviour affecting all political regimes is the key for understanding the global \\ crisis and how to get out of it. Indeed, the socio-psychological mechanisms at stake \\ are the same for climate change and for the macroeconomic deadlocks as well as for \\ the asymmetric dollar-based IMS. The principles at work in $\mathrm{CO}_{2}$ greenhouse effects ${ }^{5}$
}

\footnotetext{
${ }^{5}$ Global warming resulting from the $\mathrm{CO}_{2}$ greenhouse effect, which was discovered by Joseph Fourier in 1824, was scientifically established in 1856 by Eunice Newton Foote, an American woman, who was not credited for her discovery due to being a female and suffragette. History attributes the discovery to John Tyndall, who 'rediscovered' it in 1859. In 1896, Svante Arrhenius (Swedish Nobel Prize winner) recalculated it. Further analysed in 1939 by Guy Stewart Calendar, it was demonstrated empirically in 1953 by Gilbert Plass and in 1957 by Roger Revelle and Hans Suess. The concept was diffused pedagogically by the magazines Time, Life, and in 1958 by the 'Bell Science Hour' and through a popular movie by Frank Capra. As of the 1950s, energy companies ordered several scientific studies, all concluding there was a causal link between the use of fossil fuels and global warming, implying therefore a questioning of their future exploitation and profits. In 1958, Revelle and Keeling started to measure a daily record of $\mathrm{CO}_{2}$ concentration, based upon which the so-called Keeling curve shows that $\mathrm{CO}_{2}$ emissions were accelerating and reaching a record level in 3 million years. On these bases, as of 1960, the Jason Committee (a secret group of elite scientists which advises the US government on strategic security matters of science and technology) used MacDonald's model on climate change to convince US presidents (beginning with John Kennedy in 1961) that fossil fuel burning would lead to dangerous global warming that would endanger the planet. These analyses all concluded by proving the reality of global warming due to fossil energy and the need for urgent actions and for launching international measures, including Revelle and Keeling's report in 1977 and the Charney Report in 1979 ('Carbon Dioxide and Climate: A Scientific Assessment'), from which several initiatives emerged, such as the international carbon tax proposed by William Nordhaus (Carter's economic adviser and Nobel Prize winner in 2018), Carter's 'Changing Climate' report (published in 1983) and the report by the Environment Protection Agency, both of which scientifically confirmed Charney's alarming report and warned that it was urgent (and maybe too late) to act, but all were blocked or abolished by President Reagan in the 1980s and the US press, influenced by lobbies seeking to divert the scientific conclusions through the counter-argument that market forces would take charge, thanks to the US scientific progress to come, therefore opposing any costly changes to the US economy. During the 1988 presidential campaign, G. Bush took the electoral commitment to act for curbing global warming, but the fossil energy industry and their major users organized a massive campaign of disinformation (half a billion US dollars only in 1989 and 2 billion between 2000 and 2016), throwing doubts upon the scientific basis of climate change risks and timing. In spite of a growing international consensus for an international treaty to limit $\mathrm{CO}_{2}$ emissions with carbon taxes, the vested interests won the battle with the decisive influence of John Sununu (the head of the Bush administration), who kept the Noordwijk Conference (November 1989) from enacting an interna-
} 
as well as those in any externality, ${ }^{6}$ the near-sighted financial market ${ }^{7}$ and asymmetry in the IMS, ${ }^{8}$ have been scientifically known and explained extensively for more than half a century. In spite of all the necessary information, both the scientific community and policymakers have acknowledged that the huge gap between the causes and the effects was making it too difficult and too risky for there to be any effective action to face powerful lobbies because the value of the future was too low compared to the immediate economic advantages for citizens resulting from burning fossil fuels: all the progress in well-being since the industrial revolution has been produced by the (overly) low price of energy afforded by burning fossil combustibles. Such a generalized procrastination has also been observed in the financial and monetary fields, where the establishment strongly defends the status quo against regulations and changes in the IMS.

...helps to identify the roots of our unsustainability in our materialist rationality, with its male binary order resulting from the evolutionary process that was necessary for our past survival and economic development...

This crazy race towards human destruction is based upon much deeper aspects that analyses of economic or political economy might make clear. We are convinced that pure economic mechanisms must be viewed as reflecting our 'binary thinking' bias. The way we think and base our scientific analysis is very 'male-oriented'. This seems to be the result of millions of years of evolutionary progress based upon a primitive survival selection, combined later with the rationality built upon the postSocratic philosophy ${ }^{9}$ imposed by thousands of years of economic selection. Such a double natural selection has introduced fatal contradictions into our global economic system which counteract our own pretention to materialist efficiency and progress in productivity. As Sarah Myhre (2019) argues, not only is gender inequality not a 'natural law', but it is a monstrous unnatural bias destroying nature itself. In the American Andes, the 'Pachamama' - a feminist Amerindian concept that personalizes mother nature - transforms the abusive rationality of the male predator into a rape which is eventually castigated by the self-destruction of its unnatural material results, turning the expected material benefits and rationality into negative output, i.e. showing the irrational male behaviour. Therefore, the survival of not

tional compulsory limitation of $\mathrm{CO}_{2}$ emissions. The doubts about the existence of global warming due to $\mathrm{CO}_{2}$ are now scientifically discarded because, contrary to previous historic climatic changes, this time the changes are global, i.e. simultaneously observed on all continents.

${ }^{6}$ The inefficiencies due to externalities in market economies were explained by Alfred Marshall in 1890 and elaborated by A. Pigou in 1920 and are an indisputable part of Economics.

${ }^{7}$ The instability of financial markets was analysed by Keynes in the 1930s.

${ }^{8}$ The incoherence of the dollar-based IMS was denounced tirelessly by Triffin from the 1950s up to his death in 1993.

${ }^{9}$ Plato and Aristotle believed that nature ordained not only physical differences between males and female but mental differences as well, declaring that women were incapable of reasoning and as such subjected to men: 'Nature makes women inferior to men'. This long-lasting exclusion of half of humanity has had severe consequences for peace, human harmony, economic and political development and respect for life and our planet. See Whitbeck (1976) and Maloney (1991). 
only our own civilization but furthermore that of humankind would depend on our ability to resolve the gender issue.

Admittedly, the cultural rationality has demonstrated its efficient supremacy. Indeed, the progressive emergence of Western societies and their temporary material superiority with the industrial revolution and its accelerated global extension are the positive results of fragmented analyses and binary belief cultures. However, these material successes are only one side of the real world. Negative spillovers and perverse effects are becoming now explicit and visible. So far, the institution of a rational materialistic science has imposed a 'dictatorship of reason and materialism ${ }^{10}$ in which science is not about developing human consciousness and life in a holistic approach to the planet but about power and money in a linear, fragmented, male binary hierarchical order. This order and its spectacular material results have produced a terrific illusionary bias by separating our perception of our power from our impacts on life and our planetary systems. One example is the fact that economic growth and its measure in terms of GDP have become a pathetic illusion as far as the negative output of $\mathrm{CO}_{2}$ emissions and other depletions of natural species and resources are not taken into account in the statistics. The result is a predatory, unfair attitude on the part of the present generation against subsequent ones and of the richest against the poorest.

...but paradoxically this successful, historic evolutionary process has become a destructive natural process...

Presently, the systemic difference between this crisis and the previous ones is based upon the fact that the individual (male) genetic motor which permitted an overcoming of previous material constraints and shaped our 'way of thinking' has become itself the cause of the problem of unsustainability. According to neuroscience - which will not be developed here since it lies outside the scope of the present research $^{11}$ - the most fundamental reason for the process of destruction of life on Earth is based upon our brain structure, which has selected a segmented way of thinking necessary for ensuring our material success and the industrial revolutions. The resulting economic supremacy has pushed the world toward a male rationality based upon a binary method that has led to a dichotomist conception of life, which

\footnotetext{
${ }^{10}$ See the work of Francisco Varela and the Santiago School of Cognition, e.g. Varela et al. (2016).

${ }^{11}$ The deeper roots of Western societies' rationality extend far beyond the Enlightenment to the whole post-Socratic way of thinking in Western cultures. See the 'Institute of Human Conductivity', founded by Carlos Gonzalez Carrasco and based at Regent's University, London, www.humanconductivityinstitute.com: 'The old scientific narrative is practiced as an exclusive binary. The practices of scientific materialism have caused a brutal process of dehumanisation and the unprecedented destruction of our planet. Dominant "rational-logical" scientific materialistic practices have reduced life to a degraded, debased and undignified monetised commodity. It has fragmented and separated our mind from our body, our body from our spirit, human from humans and humans from nature. This is a catastrophic and collective failure of human thinking. The old fixed and rigid scientific paradigms and dogmas have decayed to the point of an irreversible collapse, a process of continuous systemic crisis of its individual parts (corporate, economic, political, social, ecological, spiritual, moral, ethical) but for HCI these individual expressions are in fact parts of a systemic crisis of the whole'. See also Ghymers and Gonzalez Carrasco (2016).
} 
in turn has created an 'illusory commodified reality' that is engaging humankind in a dehumanized deadlock (Gonzalez Carrasco 2017) and a fictitious immediate well-being.

Such a destructive 'natural selection' seems to respond to an individual brain structure that has been shaped by millions of years of survival struggle but that has been unable, as a result of the actions of dopamine incentives, to spontaneously take into account a collective global constraint and a long-term improvement instead of an immediate satisfaction. As explained by S. Bohler (2019), the human brain balances immediate ('animal') impulses controlled by the striatum (mesencephalon) and the (human) capacity to assess and plan for the future managed by the cortex (frontostriatal fibres). The striatum was configured by the past animal fight for survival, which needed to give priority to immediate advantages when individuals were in competition in the natural selection process, while the cortex development emerged later in human societies as a result of the rational preference for the future.

...through an imbalance that is favourable to populism, which draws upon immediate impulses instead of forecasting rationality...

Nevertheless, the recent technological and economic progresses combined with the uncertain climate created by the global crisis have developed a culture biased towards instantaneity, which tends to weaken the countervailing power of our cortex upon our animal striatum through the issuance of dopamine that is neurochemically dominated by our animal nature. The result would be a trend favourable to the 'me now' of materialism and to short-term profits through individual brains in competition that prefer immediate advantages when uncertainty reigns.

This universal phenomenon, which is referred to as the psychological 'temporal loss of valorisation', is not new but has been compensated by the easy economic growth of the pre-global crisis period, during which apparently rapid productivity increases combined with social protection fed an illusionary security. The generalization of economic uncertainty with the global crisis has created a sociopsychological shock of popular fears, which weakens the collective ability to plan for the future. The popular reflex of fear gives preference to the immediacy supported by the memory of the past, 'democratically' refusing any longer-term considerations, rejecting the elites in power viewed as necessarily guilty for the current deteriorations and, opting for status quo, condemning democracy to populism. This risk was spectacularly illustrated by the recent French social revolt of the 'gilets jaunes', in which $80 \%$ of the citizens opted for the immediate purchasing power advantages of lower oil prices and deficit spending at the expense of the longer-term collective interests of financing the energy transition. ${ }^{12}$

...leading 'ceteris paribus' to a civilizational collapse...

Our current sustainability crisis is the result of all the negative human impacts on our vital planetary eco-systemic interdependencies, which the materialistfragmented-rationality paradigm ignores by maintaining an illusory reality. As

\footnotetext{
${ }^{12}$ Of course, such a populist rejection of longer-term rationality was spurred and amplified by the lack of fair distribution in the government measures. However, most of their claims reflect the desire for immediacy instead of systemic improvements.
} 
already denounced some 20 years ago by Tom Bentley and Daniel Stedman Jones (2001, p. 16), this triumph of individualism, still superficially defensible in terms of social progress and justice, has most obviously contributed to the loss of faith in the democratic frameworks and cultures which previously underpinned common life. In every industrialised society, willingness to vote and place confidence in public institutions has steadily declined....but the collective consequences of unchecked individualism, and its primary form of agency - market exchange - present basic challenges not just to those societies in terms of their cohesiveness and quality of life, but also to the world as a whole.

Since the method of Western thinking has led to an efficient conquest of power and impressive technical and economic performance based upon predominantly materialist cultures and apparently scientific arguments, a natural selection process has diffused it globally. With this irreversible expansion, the inner caveats of Western materialism (both capitalist and socialist) have been accumulating behaviours that are exponentially destructive for humanity and ecological systems, with counterproductive socioeconomic results that generate exponentially growing economic costs, which are leading to civilizational collapse. The reason for this threat is the difficulty for a male culture to become more aware of the interdependent and unitary nature of life as a whole when money is the main power and tends to be concentrated and used by vested interests for exploiting the animal-male determinisms in people. Regulations have been systematically reduced or inhibited by dogmatic reasoning without any scientific basis but merely driven by vested interests and rent-seeking abuses created by this imbalanced male culture.

... because the strict law of universal entropy is not counteracted by a systemic organizational progress towards a multilateral governance in the financial and environmental areas...

The most visible proof of the wrong direction of a 'simulated materialistic reality' is simply the deadlock created by our inability to wean our dependencies on fossil fuels, explained - on top of obscure manipulations from vested interests and conspiring ideologies - by our lack of vision and collective support for organizing the deeper systemic transformation urgently required to ensure an economic sustainability capable of safeguarding life and democracy through an effective multilateral governance for regulating international trade and finance.

Among the main results of the joint research of this Jean Monnet Network is the identification of a global systemic failure in the present economic order, which explains the current sustainability crisis and the impossibility of breaking the status quo in order to implement multilateral solutions. This present deadlock represents the major challenge for the survival of humankind. The window of opportunity for solving it is about to close in the midst of an amazing mood of civil reluctance or passivity that is putting the present world on the brink of our own civilizational collapse, which indicates that the systemic issue is much deeper and broader than its traditional economic and political domains. We are facing a very powerful paradigm; its roots are deeply genetic but have been transformed into cultural and philosophical features with a gender inequality bias. Its powerful resilience comes from the abuses of vested interests that exploit our genetic animal dependence upon 
dopamine in order to mask the growing gap between private and social returns. This abuse of power means that institutional democracy is turned into an illusion because there is no sufficient economic democracy but rather an excessive concentration of monetary power in an ethical desert. In this process, without a strong reaction in terms of 'ethical values', the emergence and achievement of 'noogenesis' ${ }^{13}$ (Teilhard de Chardin 1955), i.e. the inner social organizational forces of human life able to countervail the entropic forces, are dangerously inhibited.

\section{Some Paths Towards a Solution}

Tackling global warming requires tackling the caveats in the global financial architecture... the materialist bias of our societies...

The pyramid of unsustainability, with its 'moral hazard' process based upon price distortion mechanisms, is the expression of imbalances in the sociopolitical organizational process, i.e. the gap between political and economic democracy. Vested interests and increasingly unfair income distribution block the organizational responses to instability and inefficiencies, which are namely, reforms geared towards regulated markets and international cooperation. In particular, Triffin's 'built-in destabilizer' in the asymmetric dollar-based IMS, amplified by pro-cyclical financial markets, impedes an answer to financial needs and a price correction for solving the global warming challenge. Indeed, restoring climate sustainability requires restoring macroeconomic and financial sustainability, i.e. not only reversing the absorption of global savings by US consumers but also channelling financial flows from speculative investments to real ones capable of ensuring profitable green energy production everywhere, however mostly in emerging economies and LDCs. This change would also solve the lack of macroeconomic growth by correcting the biased relative yield between financial and real investments, making real output attractive again and reaching a convergence between private and public returns.

Of course, such an ideal response would ideally need a consensual, coordinated change at multilateral and national levels, which would require a radical change of relative values in order to give priority to a holistic view of life and long-term social interests, i.e. to ensure the organization of the 'Teilhardian noogenesis'. Being realistic, such a primary solution would take too much time and not prevent disasters, but economists could have a 'quick fix' at hand for helping social and private returns to converge through taxation/subsidy measures.

...by using precisely materialist incentives through market conformity measures...

If we admit this fact that the deepest origin of the problem is the generalized 'moral hazard' induced by the materialism with which we shape our thinking

\footnotetext{
${ }^{13}$ Teilhard de Chardin's concept of noogenesis refers to the evolutionary process by which a brighter scenario would be possible on Earth insofar as humankind could counteract the universal law of entropy by the human capacity to organize social progress and cooperation through ethical values.
} 
through a lack of ethics that leads to the predominance of insufficiently regulated market exchanges - something difficult to change in time for saving the planet - it is fortunately possible and faster to cure the 'moral hazard' issue by merely using the same materialist market mechanisms, however after correcting relative prices in order to activate decentralized incentives through fiscal policies with a revenueneutral carbon tax (fair distribution of the costs across society) combined with a withdrawal of the subsidies for fossil energies and an introduction of subsides for renewable energies. The first priority is to scrap the annual $\$ 87$ billion of implied subsidies for fossil energies (Stefanski 2017) and to increase progressively, albeit credibly, the prices of carbon emissions (including those included in all products). This is urgent for channelling financial flows to more profitable low-carbon output. In 1979, a similar correct response was already present in Nordhaus' proposal to the Carter administration, which would have been able to stop global warming but was opposed by the Reagan administration. The alternative - an ethical change - is necessary, but it relies on education and takes too much time for ensuring durable ownership.

The same mechanism of market failure that explains climate disasters is also responsible for other sustainability challenges with regard to social cohesion, lack of key public goods and macro-financial instability. All the global issues share the same systemic bias with regard to responsibilities, i.e. moral hazard. In particular, the most influential one, due to its being macroeconomic, comes from untamed financial markets based upon an asymmetrical international monetary system (IMS) that provokes global liquidity waves and spillovers through the 'exorbitant' role of the US dollar and the capital flows moved by big multinational banks. This very systemic caveat is the origin of a pyramid of costly global disturbances characterized by the fact that those responsible for the spillovers or disturbances are not those affected by the negative impacts of these behaviours. This creates a responsibility bias ('moral hazard'): 'the polluters are not the payers', but they are the exclusively short-term beneficiaries.

Therefore, climate change risks and macroeconomic instability resulting from the asymmetrical IMS are closely linked. Those risks - which are apparently very different - not only intrinsically share the same systemic origin in their inner logic but also are linked overall by their respective solutions and by their urgency.

Both global warming and the destabilizing international monetary system share the same feature that condemns our world to unsustainability and eventual fatal destruction due to their reliance upon near-sighted free market forces. Our current sustainability crisis is the main symptom of the inability of pure free market regimes as well as centralized economic regimes to generate stability together with longterm social prosperity.

Indeed, basic economics teaches that 'liberalism' is inefficient when there are significant spillovers or clear characteristics of a public good, as is obviously the case both for the global environment and for the global monetary system and its liquidity management. Unregulated free markets and uncoordinated monetary policies impede sustainable solutions and a fair supply for ensuring sustainable stability. Opposing regimes with central planning, although theoretically able to better 
control externalities than market economies, present even worse failures that result from rigid management, power concentration leading to weak incentives for innovation and the negation of human rights, as demonstrated by numerous experiences.

The deterioration of the global environment comes from negative spillovers that by definition escape adequate pricing by free markets, feeding a systemic and devastating moral hazard for governments, corporations and individuals, while on the financial side, a similar unsustainable situation is provoked by the asymmetries resulting from the use of a national currency - the US dollar - as the main international reserve currency, which, combined with the untamed financial deregulation implemented for several decades, creates disturbing global monetary spillovers that explain the succession of increasingly large crises: unmanaged liquidity waves, financial asymmetries and persistent global payment disequilibrium.

...without starting with revolutionary changes but by organizing multilateral market conformity rules within existing multilateral organizations....

Although the causes of the systemic caveats are deeply rooted in our materialist cultures and will need long-term progressive changes and more ethical values, the good news is that the required urgent changes are still possible at the technical level by merely using market-conformity interventions. Indeed, they could be organized at the multilateral level by focusing on the key mechanisms that are provoking global unsustainability and without necessarily imposing centralistic regimes but rather simple consensual regulations that draw upon relative price incentives. Of course, a minimum improvement in international cooperation is required within the existing multilateral order. This necessary international consensus is bound to appear with the increasingly alarming degree of urgency combined with the growing awareness of the nonsense of nationalistic non-cooperative options: by definition, global systemic diseases require efficient global actions. The present opposition of some national leaders cannot be an excuse for no action since there are ways to exert pressure through the formation of large international coalitions that coordinate retaliation against free riders: countervailing duties on imports with high carbon paths and exclusion from multilateral financial resources, triggering heated domestic debates inside the free-rider countries. The only immediate systemic solution to the two identified key diseases is multilateral regulation and management in order to correct market-price distortions by taking externalities (both positive and negative) into account. With regard to carbon emissions, there are some simple multilateral options for pricing carbon in order to discourage its consumption while creating incentives for alternative green energies (relative price effects created by $\mathrm{CO}_{2}$ tradable permits or UN taxation reinforced by WTO custom duties according to carbon footprint, financial green guarantees/facilities, etc.) or, in the second place, EU regional options (custom duties and subsidies) to be bargained with other regional partners or a few reluctant economies. In addition, concrete financial innovation and regulation changes are indispensable for complementing the carbon pricing positively in order to make low-carbon investment more attractive, especially in LDCs. Indeed, the magnitude of the financial resources necessary for controlling the risks of climate change seems so high (around US\$ 1 trillion yearly up to 2035, 2/3 of which in emerging/LDCs) that systemic changes are simultaneously required for the financial sector. 
Fortunately, these changes are necessary from both the social and the private profitability perspectives at a time of increasing financial uncertainty and inadequate sustainable investment in the real economy. According to Art. 2 of the Paris Agreement (COP21), there is a clear consensus between public and private actors for 'making finance flows consistent with a pathway towards low greenhouse gas emissions and climate-resilient development' (Dasgupta et al. 2018). This means that moving to a sustainable economy is not only a survival imperative but also a financial opportunity and therefore a decentralized incentive for financial reforms. This convergence opens an important window of opportunity for systemic changes in the international financial architecture.

...more precisely, the systemic solution to global warming requires a simultaneous systemic change in the international financial architecture...

Obviously, the public good nature of ensuring the transition to the new model of prosperity laid out in the UN Sustainable Development Goals and the implied massive shift of resources and output require collective action at the global level. Neither free market and national policy nor coercive centralization could alone ensure this successful transformation. This is precisely where a systemic change in decentralized incentives together with global financial regulation in a new multilateral monetary system is the necessary complement for ensuring global sustainability. No stability could result from free financial markets that cause damaging spillovers. Furthermore, globalized financial markets operate without multilateral agreement on an ultimate multilateral 'safe asset' issued by a genuine multilateral lender of last resort, i.e. a currency which would not be the debt of any country but of the whole system. Indeed, the IMS works with the dollar as a main international currency reserve, i.e. a debt - at sight of the US economy. This impedes a global regulation of liquidity since the US monetary policy is legitimately submitted to inwardslooking management and not to global stability.

Only international cooperation could elaborate and enact strong and better financial regulation, and this would take time. Nevertheless, the most direct and rapid way to act is by rebalancing the very asymmetrical - and thus unsustainable - international monetary system (IMS) by moving from the present dollar system to a multilateral reserve currency which is not the debt of any economy but by definition of the global system. In fact, the basis for such a systemic solution already exists; it is the special drawing right (SDR) created by the IMF in 1968 in order to become the main official reserve currency in a more symmetrical IMS. Indeed, the SDR would reduce the asymmetrical effects of the dollar and its consequent spillovers, enabling a collegial management of global liquidity as a global public good for the sake of world stability. Private financial actors are favourable to such a kind of improvement in the level playing field in order to ensure less financial turbulence. However, in order to become the primary solution, the present SDR needs to be upgraded through some adjustments in the IMF status in order to transform this currency basket of the five main international currencies (the US dollar, euro, pound, yen and renminbi) into a genuine multilateral currency issued directly by the IMF which would thus become a multilateral central bank. This quality would allow for organizing the clearing of international payments above national central banks and for the creation of a genuine multilateral lender of last resort, issuing the safest asset 
able to thus act upon the global monetary basis by buying or withdrawing eligible national bonds to national central banks (Ghymers 2018).

... which should make opposing interests converge in order to capitalize on profitable opportunities from a peaceful transition to a low-carbon economy...

Contrary to traditional views, it is unnecessary to rely mainly upon idealistic sponsors or massive ODA to LDCs in order to organize the financial changes because the economic crisis forces private capital to look for stable profitable investments. Sustainability - social and environmental - is becoming an attractive criterion for private returns, making it clearly feasible to establish their convergence with public (social) returns when the multilateral organization ensures a systemic correction of misleading incentives, opening the path to the 'Teilhardian noogenesis'.

An interesting observation developed by the CEPII (Aglietta and Couder) points to the effects that the move to green energy could produce upon the international financial architecture. Indeed, the hegemonic key currency of the past, the pound, was closely associated with the role of coal in the economic supremacy of the UK, while the following one, the dollar, has been closely associated with the oil markets and their crucial role in the post-Second World War period. With the urgent need for green energy markets, a massive geographical decentralization of energy production should also be able to reshuffle the key currency roles, making multi-polarization aspects essential for both financial and political stability in order to move to a multilateral key currency. Nevertheless, as clearly mentioned earlier, free financial markets are unable to ensure it due to their 'built-in destabilizer' logic. Due to the same inner reason of being a macroeconomic 'built-in destabilizer', the US dollar is unable to fulfil the role of a reliable international standard and issuer of 'safe assets'. The recent evolution towards the abuse of power, both in US macroeconomic policies (one trillion dollars of additional debt per year under Trump's presidency with visible pressures upon the FED to depreciate the reserve currency) and in other vulgar 'weaponizations' of the dollar, is accelerating the conditions for a consensus for changing the IMS in order to safeguard a financial and peaceful stability both for private and public agents. As explained, only a multilateral currency which is not the debt of any single economy can stabilize the whole system by offering the only neutral, safe asset capable of pricing all the other assets and exchange rates, preserving fully national sovereignties while collegially managing global liquidity as a public good, without any 'weaponization' or abuse.

\section{References}

Aglietta, M. (2018). Finance and macroeconomics: The preponderance of the financial cycle. Revue de l'OFCE, 2018/3, n 157, 197-224.

Artus, P. (2019). Discipliner la finance. Paris: Odile Jacob.

Bentley, T., \& Stedman, D. (2001). The moral universe. London: Demos.

Bohler, S. (2019). Le Bug Humain: pourquoi notre cerveau nous pousse à détruire la planète et comment l'en empêcher. Paris: Robert Laffont.

Dasgupta, D., et al (2018). Did the Paris agreement plant the seeds of a climate consistent international financial regime? https://hal.archives-ouvertes.fr/hal-01692879/document. Accessed 29 Feb 2020. 
de Chardin, P. T. (1955). Le Phénomène humain. Paris: Seuil.

Ghymers, C. (1986). Réagir à l'emprise du dolla. In M. Aglietta (Ed.), L'Ecu et la Vieille Dame, un levier pour l'Europe. Paris: Economica.

Ghymers, C. (2018). Overcoming the Triffin dilemma today: A plan for a stable international financial architecture. In Reinventing Bretton Woods Committee (RBWC) and The Astana International Financial Center (AFIC) (Eds.), 10 years after: The end of the familiar... reflections on the great financial economic crisis.

Ghymers, C., \& Gonzalez Carrasco, C. (2016). Can predominant intercultural management dimensions based on the binary opposition of cultural differences bridge the cultural divide between CELAC and Europe? COLLOQUE IDA -CERALE- Centre d'Etudes et de Recherches Amérique Latine - Europe, ESCP Europe Business School, Paris 2016. Shorter and edited version available at: https://www.academia.edu/27796176/The_DeHumanizing_Binary_Machina. Accessed 29 Feb 2020.

Gonzalez Carrasco, C. (October 2017). New science and human empowerment, London. Accessed $29 \mathrm{Feb} 2020$.

Hsiang, S., et al. (2017). Estimating economic damage from climate change in the United States. Science, 356(6345), 1362-1369.

Maloney, L. M. (1991). The argument for women's difference in classical philosophy and early Christianity. In A. Carr \& E. S. Fiorenza (Eds.), The special nature of women? (pp. 41-49). London: SCM Press.

Minsky, H. P. (1982). The financial instability hypothesis, capitalist processes and the behavior of the economy. In C. P. Kindleberger \& J. P. Laffargue (Eds.), Financial crises, theory, history and policy. Cambridge: Cambridge University Press.

Myhre, S. (2019). Cambio global, mujer y academia. Congreso Futuro 2019. Santiago: Pontificia Universidad Católica de Chile, January 2019.

Orléan, A. (1999). Le pouvoir de la finance. Paris: Odile Jacob.

Stefanski, R. (2017). Dirty little secrets: Inferring fossil-fuel subsidies from patterns in emission intensities. School of economics and finance discussion paper no. 1705. https://www.standrews.ac.uk/ wwwecon/repecfiles/4/1705.pdf. Accessed 29 Feb 2020.

Stern, N. (2007). Stern review: The economics of climate change - summary of conclusions. https://webarchive.nationalarchives.gov.uk/20100407163608/http://www.hm-treasury.gov. uk/d/Summary_of_Conclusions.pdf. Accessed 29 Feb 2020.

Triffin, R. (1991). The IMS (international monetary system...or scandal?) and the EMS (European monetary system...or success?). Banca Nazionale del Lavoro, quarterly review, $\mathrm{n}^{\circ} 179$, December 1991.

Varela, F. J., Thompson, E., \& Rosch, E. (2016). The embodied mind: Cognitive science and human experience. Cambridge, MA: MIT press.

Whitbeck, C. (1976). Theories of sex difference. In C. Gould \& M. Wartofsky (Eds.), Women and philosophy: Toward a theory of liberation (pp. 54-80). New York: Putnam.

Open Access This chapter is licensed under the terms of the Creative Commons Attribution 4.0 International License (http://creativecommons.org/licenses/by/4.0/), which permits use, sharing, adaptation, distribution and reproduction in any medium or format, as long as you give appropriate credit to the original author(s) and the source, provide a link to the Creative Commons license and indicate if changes were made.

The images or other third party material in this chapter are included in the chapter's Creative Commons license, unless indicated otherwise in a credit line to the material. If material is not included in the chapter's Creative Commons license and your intended use is not permitted by statutory regulation or exceeds the permitted use, you will need to obtain permission directly from the copyright holder.

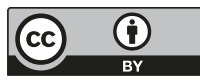

